examinations were completely unrelated to their performance as research workers. This is perhaps to be expected, for mastery of knowledge which others have produced is not an indication of ability to be creative as a scientist. Nor is it only in predicting the effective research worker that examinations are valueless. They are of little help in appraising some of the personal qualities that a good physician might be expected to have. Moreover, some qualities considered desirable in doctors are not congruent; in other words one individual cannot be expected to show all the attributes of the good physician. Direct investigation of doctors can disclose what personal abilities tend to occur in conjunction. ${ }^{6}$ But an attribute which everybody may agree is essential, like " integrity," may prove almost impossible to assess in practice. Another, like capacity for effective relationships with other people, may be easier to evaluate but may not be considered an essential requirement in a good practitioner.

Medicine is now too extensive for any one doctor to grasp even the elementary aspects of the whole field, so that limits must be set to what a medical student should be expected to know. A survey of students at Kansas showed that they were quickly disillusioned about their original naive hope to learn all there was to know, and that they rapidly changed their attitude to one of finding out "what the faculty wants them to know and learn it." 7 Medical teachers therefore have a serious responsibility to specify what knowledge and skills, and which attitudes to patients, are the hallmarks of good physicians. They have then to discover some means of assessing whether a student or a doctor possesses these qualities. Further, the importance of subjects in fields related to medicine is becoming increasingly realized. Thus, an understanding of behaviour is needed to treat patients with social and emotional components to their illness. Doctors have to respect distress without at the same time losing their objectivity. This necessary " detached concern" which is conferred by medical education and experience has been viewed in some quarters as going too far, leading to a loss of idealism, an unfortunate callousness induced by professional training. ${ }^{8}$

In time we may achieve an objective assessment of the attributes of a good doctor. We shall then be able to understand what sort of people make the best doctors (and so should not be excluded by selection methods), and decide on the type of training in undergraduate and postgraduate education. Nevertheless, as P. B. Price and his colleagues discovered, ${ }^{5}$ clinical performance is remarkably complex. They could identify more than 200 different measures of performance, some of which were applicable only to some subcategories of physicians. In Britain there are about 2.75 general practitioners per consultant, ${ }^{9}$ and clearly different skills are called for in these two professional spheres-and different again in other branches of the profession. Thus judging the performance of medical men raises complex issues that have as yet hardly been defined. The good doctor may

1 Brit. med. F., 1965, 2, 57. See also p. 373 this week.

2 The Objectives of Undergraduate Medical Education, f. med. Educ., 1953, 28, 57.

"Bloom, B. S., et al., A Taxonomy of Educational Objectives, Longmans, Green, New York, 1954.

Peterson, O. L., Andrews, L. P., Spain, R. S., and Greenberg, B. G., f. med. Educ., 1956, 31, No. 12, part 2.

Price, P. B., Taylor, C. W., Richards, J. M., and Jacobsen, T. L., ibid., 1964, 39, 203.

Walton, H. J., Drewery, J., and Philip, A. E., Brit. med. F., 1964, 2,

Becker, H. S., Hughes, E. C., Geer, B., and Strauss, A. L., Boys in White, Univ, of Chicago Press, Chicago, 1961

\& Eron, L. D., f. med. Educ., 1955, 30, 559.

Martin, F. M., and Boddy, F. A., 1962, University of Keele, Social. Rev. Monograph, No. 5.

1" Brit. med. F., 1965, 1, 1571. be defined in general and ideal terms, but he must more strictly be defined in terms of "the work which doctors should be doing during the remainder of this century"to quote from J. R. Ellis's stimulating lecture ${ }^{10}$ entitled "To-morrow's Doctors."

\section{Hand Hygiene}

The role of hands in the spread of infection was recognized by Semmelweis ${ }^{1}$ before the era of bacteriology. Indirectly, its importance is supported by bacteriological data showing that the skin carries micro-organisms ${ }^{2}$ and by the value of no-touch techniques in the application of dressings. ${ }^{3}$ More direct support comes from the recent finding that the spread of an identifiable strain of Staphylococcus aureus in a nursery was considerably less when the nurses washed their hands with a hexachlorophane detergent cream before they handled infants than if they did not. ${ }^{4}$

Surgeons have used various methods, such as antisepsis, scrubbing, and wearing rubber gloves, to protect operation wounds from contamination by the flora of the hands. For nurses and food-handlers frequent washing with soap and water is commonly assumed to be sufficient. Even prolonged scrubbing, however, removes a relatively small fraction of the skin flora ${ }^{56}$; indeed, contamination from the skin may actually be increased after washing. ${ }^{7}$ For these reasons several antiseptic preparations (notably hexachlorophane soaps and detergent creams) have been introduced in hospitals, and used repeatedly they cause, a progressive reduction in the " resident" flora of the skin. This flora sometimes includes Staph. aureus, ${ }^{8}{ }^{9}$ but other pathogens rarely colonize the intact skin, though they may be present as "transient" flora-for example, various Gram-negative rods, which are relatively insensitive to hexachlorophane. Fortunately most of these transients can easily be removed by washing with soap and water, though not even antiseptics will necessarily get rid of them completely. ${ }^{10}$

The main hazard in handling food comes from dysentery and food-poisoning organisms. Neither of these actually colonize the skin, and they can therefore be regarded as transient flora, but Staph. aureus, which is sometimes resident, may also infect the alimentary tract. Hence any routine of cleaning the hands in catering establishments should aim to remove both resident and transient flora. J. Brodie ${ }^{11}$ has recently used a simple test to assess the cleanliness of the hands of food-handlers. The hands were sampled with moistened sterile gauze squares before and after various forms of cleansing and disinfection. Total bacterial counts were obtained from nutrient-broth extracts of these squares, which were also examined for Staph. aureus and faecal Escherichia

\footnotetext{
${ }^{1}$ Sinclair, W. J., Semmelweis : His Life and His Doctrine, 1909. University Press, Manchester.

Williams, R. E. O., Bact. Rev., 1963, 27, 56

Clayton-Cooper, B., Howat, T. W., and Miles, A. A., Brit. F. Surg., 1945, 32, 425.

Mortimer, E. A., Lipsitz, P. J., Wolinsky, E., Gonzaga, A. J., and Rammelkamp, C. H., Amer. $\mathscr{F}$. Dis. Child., 1962, 104, 289.

${ }_{5}$ Price, P. B., F. infect. Dis., 1938, 63, 301.

${ }^{6}$ Lowbury, E. J. L., Lilly, H. A., and Bull, J. P., Brit. med. F., 1963, 1, 1251.

7 Speers, R., Bernard, H., O'Grady, F., and Shooter, R. A., Lancet, 1965, 1,478 .

8 Traub, E. F.,

${ }^{9}$ Lowbury, E. J. L., Lilly, H. A., and Bull, J. P., Brit. med. F., 1964; 2, 531

10 Low ibid., 1964, 2, 230.

11 Brodie, J., Scot. med. $¥ ., 1965,10,115$.

12 Wedderburn, D. L., Brit. F. industr. Med., 1960, 17, 125.
} 
coli. Brodie's experiments showed the dangers of using communal towels; they also illustrated the ready removal of $E$. coli but the persistence of Staph. aureus after washing, and the notorious variability in results of skin disinfection as judged by removal of resident bacteria. Brodie therefore concluded that it was a waste of time to take bacterial counts from hands as a test of cleanliness.

By measuring the variation in bacterial samples from skin it has been shown by statistically designed experiments that effectiveness of methods of disinfection varies widely. The application to the dry skin of creams or jellies containing hexachlorophane, chlorhexidine, or other antiseptics causes little or no reduction in the resident flora ${ }^{9}$ - though this may lessen subsequent contamination ${ }^{10}$ and remove transient flora. ${ }^{12}$ Much larger effects against the resident flora are obtained by repeated rinsing with $0.5 \%$ chlorhexidine solution or (more conveniently) by regular washing with antiseptic detergent preparations, such as povidone iodine surgical scrub or hexachlorophane liquid soap. The number of transient organisms is reduced about equally by washing with a detergent (even soap) ${ }^{10}$ as by applying a cream containing benzalkonium chloride, which has been advocated for food-handlers. ${ }^{12}$ The addition of certain antiseptics (such as povidone iodine) to the detergent increases this effect.

Whichever of the effective methods is adopted, its full value can be obtained only by repeated and consistent use of the antiseptic while the person is handling food. Moreover, all the other relevant principles of hygiene and asepsis must not be forgotten; even the best hand-cleansing routine cannot be expected to make a surgeon with boils a safe operator or a salmonella carrier a safe handler of food.

\section{Pituitary Hormones for Infertility}

Replacement therapy has now made it possible to offer some hope to the small group of women with infertility due to isolated deficiency of the pituitary gonadotrophic hormones. Failure of the pituitary to produce gonadotrophins may be due either to total failure of pituitary function (when the other hormones, such as growth hormone, thyroid-stimulating hormone, and adrenocorticotrophic hormone, will also not be produced), or to an isolated failure of gonadotrophin secretion. Clinically the latter will result in primary or secondary amenorrhoea in women, and hypogonadism in men.

Gonadotrophic hormones have two main roles in ovulation. First, follicle-stimulating hormone (F.S.H.) stimulates the maturation of an immature ovarian follicle. Secondly, luteinizing hormone (L.H.) is responsible for the shedding of the ripe ovum and the formation of the corpus luteum. For some time it has been possible to make preparations with luteinizing activity from human pregnancy urine (human chorionic gonadotrophin), but there has been no correspondingly readily available source of F.S.H. Furthermore, unlike some other pituitary hormones, such as thyrotrophic hormone and adrenocorticotrophic hormone, F.S.H. is species-specific, so that extracts of animal pituitary glands are ineffective.

Seven years ago, however, workers in Sweden, led by C. A. Gemzell, ${ }^{1}$ reported that they had been able to prepare F.S.H. from extracts of human pituitary glands obtained at necropsy ; subsequently extracts of human menopausal urine were shown to be similarly potent. In Britain the collection of pituitary glands is now undertaken by the Medical Research Council. At first these are sent to the department of biochemistry at Cambridge, where extracts of growth hormone are prepared. Subsequently the residue is used by the group working in Birmingham as a basis from which to prepare extracts of F.S.H., and preparations have been made available to several groups working elsewhere in Britain. Extracts of F.S.H. have also been prepared commercially from human menopausal urine, but are not generally available at present in this country.

Another substance known to have follicle-stimulating properties is the synthetic substance clomiphene, though the mechanism of its action is unknown. Because it is easy to make, however, it is possible that it may eventually supersede the use of pituitary extracts in treatment, though clinical trials of its efficacy are still in progress.

Clearly any patient considered for this treatment must be referred to a specialized endocrinological unit, for it is indicated in only very few of the large number of patients who complain of infertility. At present the main indications for gonadotrophin therapy would seem to be patients with established secondary amenorrhoea or anovulatory menstrual cycles in whom assays have shown that pituitary gonadotrophins are absent. It is important that too much of the hormone is not given; otherwise, overstimulation of the ovaries results in the formation of large, tender, polycystic ovaries, which may rupture and present as an acute abdomen. Another effect of overstimulation is the release of more than one ovum per menstrual cycle, resulting in multiple pregnancy. Dosage is still a paramount problem, but some sort of guide is obtained by measuring the response of the ovaries to test doses of F.S.H. F.S.H. is then given daily by injection for about ten days, being supplemented by one injection of human chorionic gonadotrophin on the final day.

If the findings of the Birmingham group are confirmed individual control of dosage would now seem to be within our grasp. The exchange of information during the Annual Endocrine Conference in Hamburg this week will undoubtedly increase our understanding of this therapy, and the results are awaited with interest.

\section{Sarcoidosis of the Nervous System}

The diagnosis of sarcoidosis is most acceptable when the characteristic clinical picture is associated with histological evidence of sarcoid tissue. The latter may be obtained by biopsy of accessible skin lesions or an enlarged lymph node; by blind biopsy of liver, muscle, or scalene lymph node ; or by means of the Kveim test. Biopsy of nervous tissue is rarely undertaken because of its relative inaccessibility, and so histological confirmation of neurological sarcoidosis is often lacking. The same drawback makes it equally difficult to be dogmatic about the occurrence of myocardial sarcoidosis. Evidence of lesions in either system is circumstantial and inferred from disordered function of the heart or nervous system in a patient who is known to have disseminated sarcoid lesions.

The definition of neurological sarcoidosis has recently been clarified by the simultaneous publication of an American ${ }^{1}$ and a British report. ${ }^{2}$ L. E. Siltzbach and his colleagues ${ }^{1}$ observed it in 18 out of 450 (4\%) patients with histologically 